\title{
Rosiglitazone shows partial oncostatic effect in rat mammary carcinogenesis
}

\author{
B. BOJKOVA ${ }^{1, *}$, K. KAJO $^{2,3}$, M. GARAJOVA ${ }^{1}$, P. KUBATKA ${ }^{4}$, M. PEC ${ }^{4}$, T. KISKOVA $^{1}$, P. ORENDAS ${ }^{1}$, M. KASSAYOVA ${ }^{1}$, M. KORPOVA ${ }^{5}$, \\ M. MIKLOSOVA ${ }^{5}$
}

${ }^{1}$ Department of Animal Physiology, Institute of Biology and Ecology, Faculty of Science, P.J. Safarik University, Moyzesova 11, 04167 Kosice, Slovak Republic; ${ }^{2}$ Department of Pathology, Slovak Medical University and St. Elisabeth Oncology Institute, Heydukova 10, 81108 Bratislava, Slovak Republic; ${ }^{3}$ BB Biocyt, Diagnostic Centre, Ltd., Nam. L. Svobodu 1, 97401 Banska Bystrica, Slovak Republic; ${ }^{4}$ Department of Medical Biology, Jessenius Faculty of Medicine, Comenius University, Mala Hora 4, 03754 Martin, Slovak Republic; ${ }^{5}$ Department of Cell Biology, Institute of Biology and Ecology, Faculty of Science, P.J. Safarik University, Kosice, Slovak Republic

${ }^{*}$ Correspondence: bianka.bojkova@upjs.sk

Received February 23, 2012 / Accepted July 2, 2012

\begin{abstract}
Peroral antidiabetics from thiazolidinedione (glitazone) group showed oncostatic effects in preclinical models. This study evaluated chemopreventive effects of rosiglitazone in $\mathrm{N}$-methyl-N-nitrosourea-induced mammary carcinogenesis in rats. $\mathrm{N}$-methyl-N-nitrosourea was administered in two intraperitoneal doses each per $50 \mathrm{mg} / \mathrm{kg}$ b.w. between $40^{\text {th }}$ and $51^{\text {st }}$ postnatal days. Rosiglitazone was administered in a diet at a concentration of $10 \mathrm{ppm}$ and 100 ppm, respectively, 9 days before the first carcinogen dose until the termination of the experiment. During the experiment the animals were weekly weighed and palpated for the presence of mammary tumors and estimation of latency period, tumor frequency per group and animal, and tumor volume were recorded. The experiment was terminated 16 weeks after the first carcinogen dose, basic tumor growth parameters and selected metabolic and hormonal variables were evaluated. Chemoprevention with higher rosiglitazone dose decreased tumor frequency per group by $44 \%$, other tumor parameters (incidence, tumor frequency per animal) were decreased insignificantly (at both doses), latency period was not changed. Rosiglitazone administration decreased cumulative tumor volume, more efficiently at lower dose. Glycaemia and insulinaemia decreased after lower rosigitazone dose administration but glycaemia did not exceed normal values. Higher rosiglitazone dose alleviated some metabolic alterations resulting from cancer progression more effectively but induced a prominent cardiac hypertrophy.
\end{abstract}

Key words: rosiglitazone, rat, mammary carcinogenesis, $N$-methyl-N-nitrosourea, metabolism

Pathways regulating cell proliferation and glucose homeostasis are interconnected which is supported by higher cancer incidence in diabetic patients [1-3]. Impaired insulin signaling shifts the balance between two counteracting pathways, anabolic mTOR (mammalian target of rapamycin) and catabolic AMPK (adenosine monophosphate-activated protein kinase), towards mTOR which results in increased cell proliferation and supports carcinogenesis [4-7]. AMPK activators such as metformin (a widely used peroral antidiabetic drug from biguanide group) inhibit various cancers both in vitro and in vivo and clinical results of metformin support its role in reducing cancer risk in diabetic patients too [8,9]. Another group of peroral antidiabetics, thiazolidinediones (such as pioglitazone and recently suspended rosiglitazone) exert onco- static efficacy as well, which was reported in numerous studies [10-12]. Thiazolidinediones are selective agonists of peroxisome proliferator-activated receptor $\gamma(\operatorname{PPAR} \gamma)$ which belongs to PPAR family, a group of transcription factors involved in controlling metabolism, cell growth, angiogenesis, and immune and inflammatory responses [13]. Antitumor activity of thiazolidinediones has been attributed to activation of PPAR $\gamma$ receptors but cancer cell growth inhibition independent of $\operatorname{PPAR} \gamma$ was also reported $[14,15]$. Thiazolidinediones activate AMPK too [16,17], which contributes to their oncostatic efficacy and other mechanisms may be involved as well, such as aromatase inhibition [18].

In vivo reports on thiazolidinediones confirmed their anticancer efficacy too, but it should be emphasized they are 
much less in number. Animal studies showed inhibition of glioma [19,20], neuroblastoma [21,22], lung [23], pancreatic [24], liver [25-27], colon [28], adrenocortical [29], ovarian [30,31], and melanoma cancer cells [32]. Thiazolidinedione administration inhibited mammary carcinogenesis too, which was reported by several authors including our group [33-36]. Reports on thiazolidinedione administration in cancer patients, however, are scarce. Rosiglitazone (ROS) administration in breast cancer patients was ineffective, but pioglitazone in combination with cyclooxygenase-2 inhibitors led to some response in patients with metastatic melanoma, soft tissue sarcoma, and glioma [11].

Human data on cancer incidence in diabetic patients treated with thiazolidinediones are controversial and both increased and decreased risk was reported. Recently conducted study showed decreased liver cancer incidence in pioglitazone and ROS users [37]. Govindarajan et al. [38] found a 33\% lower incidence of lung cancer in thiazolidinedione users in comparison with non-users but the duration of use was not considered and the study was not able to account for smoking history. Other trials found no difference in comparison with other treatment, however, duration response analysis was either missing [39] or did not last for more than 52 weeks [40]. Ramos-Nino et al. [41] suggested positive association between overall cancer rates and the use of thiazolidinediones, particularly ROS, and particularly among women but it should be emphasized that assessment of the risks for individual cancers was not performed. A positive but insignificant association between pioglitazone use and urothelial bladder cancer was revealed, which should be considered in patients with risk factors for bladder cancer $[42,43]$.

The aim of this study was to evaluate ROS efficacy in well-established in vivo mammary cancer model using Sprague-Dawley rats and N-methyl-N-nitrosourea as carcinogenesis inducer. The same model was used in our previous work where we confirmed antitumor property of pioglitazone [36]. Again, we chose preventive-curative model in order to cover both initiation and promotion/progression stage of carcinogenesis. As long-term thiazolidinedione administration may have some deleterious metabolic effects, we evaluated chosen metabolic and hormonal parameters in addition to tumor growth determinants.

\section{Materials and methods}

Female rats of Sprague-Dawley strain (AnLab, Prague, Czech Republic) aged 31-35 days were used in the experiment. The animals were adapted to standard vivarium conditions with temperature $23 \pm 2^{\circ} \mathrm{C}$, relative humidity $60-70 \%$, artificial regimen light:dark 12:12h (lights on from 7 a.m., light intensity 150 lux per cage). During the experiment the animals (4 per cage) were fed the Ssniff diet (Soest, Germany) and drank tap water ad libitum.

Mammary carcinogenesis was induced by $\mathrm{N}$-methylN-nitrosourea (NMU) (Sigma, Deisenhofen, Germany) administered in two intraperitoneal doses (50 mg/ $\mathrm{kg}$ b.w.), the first between $40^{\text {th }}-44^{\text {th }}$ and the second between $47^{\text {th }}$ $51^{\text {st }}$ postnatal days. NMU solution was freshly prepared prior to carcinogen administration by dissolving NMU in physiological solution (the average volume dose per rat was $0.5 \mathrm{ml}$ ).

Chemoprevention with ROS (Avandia, GlaxoSmithKline) was initiated 9 days prior to first carcinogen administration and lasted until the end of experiment - 16 weeks after the first NMU application. ROS was administered in a diet at two concentrations: $10 \mathrm{ppm}$ and $100 \mathrm{ppm}$.

Animals were randomly assigned to one of four experimental groups: (1) NMU, control group without chemoprevention; (2) NMU+ROS10, chemoprevention with ROS at a concentration of $10 \mathrm{ppm}$; (3) NMU+ROS100, chemoprevention with ROS at a concentration of $100 \mathrm{ppm}$; (4) INT, intact group. Each group except the intact group consisted of 20 animals, the intact group consisted of 10 animals. Animals were weekly weighed and palpated in order to register the presence, number, location, and size of each palpable tumor. Food and water intake during 24 hours was monitored within the $5^{\text {th }}$, $10^{\text {th }}$, and $15^{\text {th }}$ week of experiment (dated from the first NMU injection), overall in 12 measurements (4 times in a given week). Daily intake of ROS ranged from $0.14-0.22 \mathrm{mg} / \mathrm{rat} / \mathrm{day}$ in NMU+ROS10 and 1.4-2.1 mg/rat/day in NMU+ROS100, respectively.

Tumor growth parameters were evaluated in each group: tumor incidence (as the percentage of tumor-bearing animals per group), latency period (the period from carcinogen administration to the appearance of first tumor), tumor frequency per group (as the average tumor number per group), tumor frequency per animal (as the average tumor number per tumor-bearing animal in the group), and tumor volume. Tumor incidence was evaluated by Mann-Whitney U-test, other tumor parameters by one-way analysis of variance or Kruskal-Wallis test, respectively, the criterion for the choice of the relevant test was the Bartlett's number value. Tumor volume was calculated according to formula: $\mathrm{V}=\pi \cdot\left(\mathrm{S}_{1}\right)^{2} \cdot \mathrm{S}_{2} /$ $12 ; \mathrm{S}_{1}$ and $\mathrm{S}_{2}$ are tumor diameters; $\mathrm{S}_{1}<\mathrm{S}_{2}$.

In the last $-17^{\text {th }}$ week of experiment, the animals were quickly decapitated, mammary tumors were excised and weighed and tumor size was recorded. Macroscopic changes in selected organs (liver, spleen, kidney, stomach, intestine, and lung) were evaluated at autopsy. Tumor samples were taken for histopathological analysis. The tumors were classified according to the criteria for the classification of rat mammary tumors [44]. Basic metabolic and hormonal parameters were determined in serum and selected organs: serum concentration of glucose (GLU); serum and liver concentration of triacylglycerols (TAG), cholesterol $(\mathrm{CH})$, and phospholipids (PL); liver and heart muscle glycogen (GLY) concentration; liver and thymus malondialdehyde (MDA) concentration; serum corticosterone (CTS), insulin (INS), and IGF-1 concentration. GLU and TAG were measured using commercial sets (PLIVA-Lachema, Brno, 


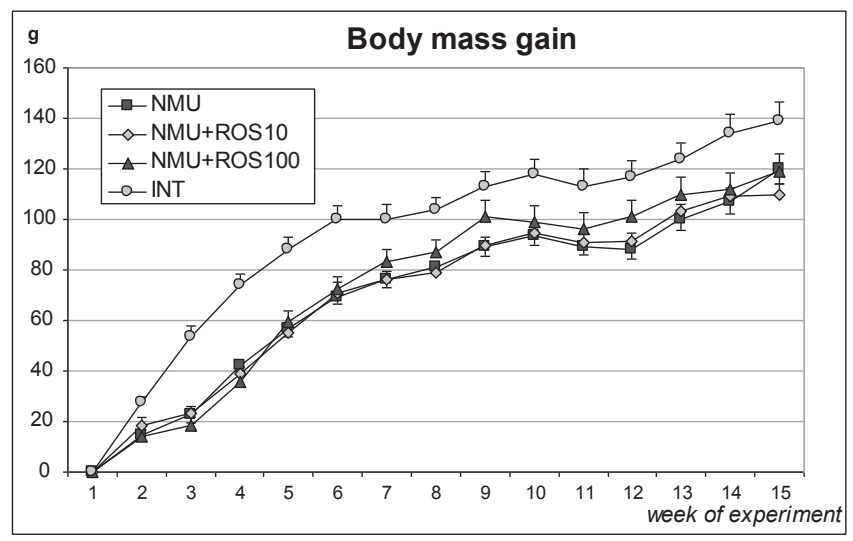

Figure 1. The effect of rosiglitazone in NMU-induced mammary carcinogenesis in Sprague-Dawley rats on body mass gain.

Data are expressed as means \pm S.E.M. For significant differences between groups see the Results section. Abbreviations: NMU - control group without chemoprevention, NMU+ROS10 - chemoprevention with rosiglitazone $(10 \mathrm{ppm})$, NMU+ROS100 - chemoprevention with rosiglitazone (100 ppm), INT - intact group

Czech Republic), INS concentration was determined using commercial RIA set (DRG Instruments GmbH, Germany) and IGF- 1 concentration was determined using commercial ELISA set (DRG Instruments GmbH, Germany). PL were measured from lipid phosphorus according to Bartlett et al. [45], CH according to Zlatkis et al. [46], GLY according to Roe and Dailey [47], MDA was measured in reaction with thiobarbituric acid according to Satoh [48], CTS was measured using fluorimetry according to Guillemin et al. [49]. Metabolic and hormonal parameters were evaluated by one-way analysis of variance. The experiment was carried out from November to March. The animals were treated according to the principles provided in the Law No. 289/2003, $489 / 2003$, and 23/2009 of Slovak Republic for the Care and Use of Laboratory Animals.

\section{Results}

Carcinogen administration reduced body mass gain in all experimental groups during the whole experiment, periovarial fat weight declined as well, this was accompanied by decrease in food intake (which was significant in $5^{\text {th }}$ and $15^{\text {th }}$ week of experiment). Higher ROS dose normalised food intake without impact on body and adipose tissue weight. Water intake in NMU+ROS100 remained increased till $15^{\text {th }}$ week of experiment (Figure 1, Table 1).

Tumor incidence declined insignificantly after ROS administration (by $26 \%$ and $24 \%$, respectively) latency period was not changed. Higher ROS dose decreased tumor frequency per group by $44 \%$, in NMU+ROS10 group this decline was not significant (by $38 \%$, Figure 2), frequency per animal declined insignificantly after both doses (by $16 \%$ and $26 \%$, respectively). Insignificant tumor volume decrease (by $32 \%$ ) was recorded after lower ROS dose. ROS administration decreased cumulative tumor volume, more efficiently at lower dose (Table 2).

Table 1. Chemoprevention of NMU-induced mammary carcinogenesis in Sprague-Dawley rats by rosiglitazone: food and water intake.

\begin{tabular}{|c|c|c|c|c|c|}
\hline \multirow[b]{2}{*}{$\mathbf{n}$} & & $I N T$ & $N M U$ & $N M U+R O S 10$ & $N M U+R O S 100$ \\
\hline & & 10 & 20 & 20 & 20 \\
\hline \multirow[t]{2}{*}{$5^{\text {th }}$ week } & Food intake (g/rat/day) & $23.1 \pm 0.754$ & $\begin{array}{c}18.8 \pm 0.411 \\
\text { aaa }\end{array}$ & $19.1 \pm 0.475$ & $20.2 \pm 0.307$ \\
\hline & Water intake (ml/rat/day) & $32.7 \pm 0.993$ & $31.8 \pm 0.461$ & $30.5 \pm 0.650$ & $\begin{array}{c}33.0 \pm 0.784 \\
\text { b }\end{array}$ \\
\hline \multirow[t]{2}{*}{$10^{\text {th }}$ week } & Food intake (g/rat/day) & $17.7 \pm 0.979$ & $15.8 \pm 0.416$ & $16.5 \pm 0.426$ & $\begin{array}{c}17.4 \pm 0.471 \\
\uparrow\end{array}$ \\
\hline & Water intake (ml/rat/day) & $26.7 \pm 1.48$ & $25.7 \pm 0.863$ & $25.3 \pm 0.612$ & $\begin{array}{c}28.5 \pm 0.705 \\
\uparrow \mathbf{b b}\end{array}$ \\
\hline \multirow[t]{2}{*}{$15^{\text {th }}$ week } & Food intake (g/rat/day) & $19.7 \pm 0.657$ & $\begin{array}{c}17.6 \pm 0.459 \\
\mathbf{a}\end{array}$ & $17.2 \pm 0.655$ & $\begin{array}{c}19.2 \pm 0.500 \\
\uparrow \mathbf{b}\end{array}$ \\
\hline & Water intake (ml/rat/day) & $34.4 \pm 1.96$ & $\begin{array}{c}29.2 \pm 0.887 \\
\mathbf{a}\end{array}$ & $28.8 \pm 1.47$ & $31.7 \pm 1.39$ \\
\hline \multicolumn{2}{|c|}{ Periovarial fat weight $(\mathrm{g})$} & $5.23 \pm 0.556$ & $\begin{array}{c}3.40 \pm 0.276 \\
\text { aa }\end{array}$ & $3.78 \pm 0.316$ & $3.01 \pm 0.162$ \\
\hline \multicolumn{2}{|c|}{ Final body mass gain (g) } & $139 \pm 7.50$ & $\begin{array}{c}120 \pm 5.75 \\
\text { aa }\end{array}$ & $110 \pm 4.20$ & $119 \pm 6.87$ \\
\hline
\end{tabular}

Data are expressed as means \pm S.E.M. Significant differences between groups are designated as follows: NMU vs INT: a P $\leq 0.05 ; \mathbf{a a} P \leq 0.01 ; \mathbf{a a a} P \leq 0.001$; an increase of given parameter in groups with chemoprevention (NMU+ROS10, NMU+ROS100) vs NMU: $\uparrow \mathrm{P} \leq 0.05 ; \mathrm{NMU}+\mathrm{ROS} 10$ vs NMU+ROS100: b $\mathrm{P} \leq 0.05$, bb $\mathrm{P} \leq 0.01$.

Abbreviations: INT - intact group, NMU - control group without chemoprevention; NMU+ROS10 - chemoprevention with rosiglitazone (10 ppm), $\mathrm{NMU}+\mathrm{ROS} 100$ - chemoprevention with rosiglitazone (100 ppm), $\mathrm{n}$ - number of animals at the beginning of the experiment 
The number of non-tumor-bearing animals as well as total tumor number was lower in groups with chemoprevention when compared to control group. Histologically, there were no distinct differences in abundance of the carcinomas among groups. Mixed low-grade papillary and cribriform carcinoma was the most common tumor type. A bit higher ratio between low-grade/high-grade carcinomas was documented in NMU+ROS10 group, this ratio was balanced in the other groups. The interesting finding was a presence of 11 atypical tumor-like lesions localised in the lower lateral parts of the body in NMU+ROS100 group, whereas only one such lesion occurred in NMU+ROS10 group and none in untreated animals. Histological examination of these lesions revealed lipomatous origin associated with spindle cell proliferation and fat necrosis which confirmed regressive pattern (Table 3).

Metabolic alterations after ROS administration were inconsistent. Glycaemia and insulinaemia was lower in $\mathrm{NMU}+\mathrm{ROS} 10$ group, higher ROS dose increased both glucose and insulin concentration to the level of control (and intact) group but glycaemia in all groups did not exceed normal range. Carcinogen administration induced glycogen accumulation both in liver and heart muscle, ROS administration decreased it below the intact level. Serum TAG concentration increased and liver TAG concentration decreased after carcinogen administration, ROS in lower dose normalised liver TAG concentration. ROS in higher dose increased serum $\mathrm{CH}$ concentration (which dropped in control group), both doses decreased liver $\mathrm{CH}$ concentration without dose-dependent manner. Serum PL concentration increased after higher ROS dose, in liver, both ROS doses decreased PL concentration. Lower ROS dose unexpectedly increased serum CTS concentration. Carcinogen administration increased liver (but not thymus) MDA concentration, higher ROS dose decreased it to the level of intact group. In thymus MDA concentration surprisingly rose after lower ROS dose. Higher ROS dose increased liver relative weight and heart muscle weight, both absolute and relative (calculated as percentage of body weight). Serum IGF-1 concentration

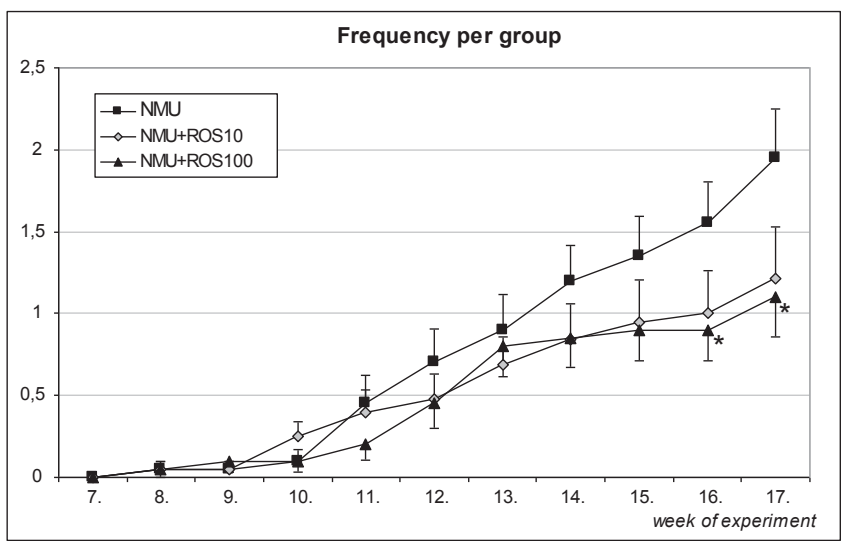

Figure 2. Chemoprevention of NMU-induced mammary carcinogenesis in Sprague-Dawley rats by rosiglitazone: tumor frequency per group Data are expressed as means \pm S.E.M. Significant differences between groups are designated as follows: NMU vs NMU+ROS100: $* \mathrm{P} \leq 0.05$. Abbreviations: $\mathrm{NMU}$ - control group without chemoprevention; NMU+ROS10 - chemoprevention with rosiglitazone (10 ppm), NMU+ROS100 - chemoprevention with rosiglitazone (100 $\mathrm{ppm})$.

increased in NMU+ROS10 group in comparison with NMU and NMU+ROS100 group (Table 4).

\section{Discussion}

Despite vast evidence on thiazolidinedione anticancer properties, most data come from in vitro studies and therefore omit the host response. Besides, in vivo studies should focus more on effects of long-term administration in order to reveal possible side effects which could contraindicate treatment in human subjects at certain risk. Until recently, two peroral antidiabetics from thiazolidinedione group had been used in diabetes type 2 treatment: pioglitazone and ROS, but because of increased risk of myocardial infarction [50], which will be discussed further, ROS was suspended from the European market in September 2010. In the U.S.A,

Table 2. Chemoprevention of NMU-induced mammary carcinogenesis in Sprague-Dawley rats by rosiglitazone: tumor growth parameters

\begin{tabular}{lccc}
\hline & NMU & NMU+ROS10 & NMU+ROS100 \\
\cline { 2 - 4 } $\mathbf{n}$ & 19 & 19 & 20 \\
\hline Incidence (\%) & 85 & $63(-26 \%)$ & $65(-24 \%)$ \\
Latency (days) & $79.1 \pm 3.71$ & $73.4 \pm 4.73(-7 \%)$ & $74.9 \pm 3.35(-5 \%)$ \\
Frequency per group & $1.95 \pm 0.303$ & $1.21 \pm 0.321(-38 \%)$ & $\mathbf{1 . 1 0} \pm \mathbf{0 . 2 4 0}(\mathbf{- 4 4 \% )} *$ \\
Frequency per animal & $2.29 \pm 0.281$ & $1.92 \pm 0.379(-16 \%)$ & $1.69 \pm 0.237(-26 \%)$ \\
Tumor volume $\left(\mathbf{c m}^{3}\right)$ & $0.954 \pm 0.326$ & $0.645 \pm 0.228(-32 \%)$ & $0.991 \pm 0.232(+4 \%)$ \\
Cumulative tumor volume $\left(\mathbf{c m}^{3}\right)$ & 36.3 & 14.8 & 21.8 \\
\hline
\end{tabular}

Data are expressed as means \pm S.E.M. Significant differences between groups are designated as follows: NMU vs NMU+ROS100: $*$ P $\leq 0.05$. Abbreviations: NMU - control group without chemoprevention; NMU+ROS10 - chemoprevention with rosiglitazone (10 ppm), NMU+ROS100 - chemoprevention with rosiglitazone (100 ppm), $\mathrm{n}$ - number of animals per group. 
Table 3. Chemoprevention of NMU-induced mammary carcinogenesis in Sprague-Dawley rats by rosiglitazone: histopathology of mammary tumors

\begin{tabular}{|c|c|c|c|c|c|c|}
\hline \multirow{2}{*}{$\begin{array}{l}\text { Mammary tumors } \\
\text { Malignant lesions }\end{array}$} & \multicolumn{2}{|c|}{ NMU } & \multicolumn{2}{|c|}{ NMU+ROS10 } & \multicolumn{2}{|c|}{ NMU+ROS100 } \\
\hline & HG & LG & HG & LG & HG & LG \\
\hline Papillary and cribriform carcinoma & 4 & 11 & 2 & 5 & 1 & 8 \\
\hline Cribriform carcinoma & 5 & 1 & 2 & 1 & 3 & 1 \\
\hline Cribriform and comedo carcinoma & 4 & - & 3 & - & 2 & - \\
\hline Papillary, cribroform, and comedo carcinoma & 4 & - & - & - & 3 & - \\
\hline Papillary carcinoma & - & 3 & - & 3 & 1 & - \\
\hline Cribriform and papillary carcinoma & - & 3 & - & 4 & - & - \\
\hline Sarcoma & - & - & - & 1 & - & 1 \\
\hline Cribriform, papillary, and comedo carcinoma & 1 & - & - & - & - & - \\
\hline Tubular carcinoma & - & - & 1 & - & - & - \\
\hline Ductal carcinoma in situ, cribriform type & - & - & - & - & - & 1 \\
\hline Total high/low grade ratio & \multicolumn{2}{|c|}{$18 / 18$} & \multicolumn{2}{|c|}{$8 / 14$} & \multicolumn{2}{|c|}{$10 / 11$} \\
\hline \multicolumn{7}{|l|}{ Benign lesions } \\
\hline Tubular adenoma & \multicolumn{2}{|c|}{-} & \multicolumn{2}{|c|}{-} & \multicolumn{2}{|c|}{1} \\
\hline Total tumor number & \multicolumn{2}{|c|}{36} & \multicolumn{2}{|c|}{22} & \multicolumn{2}{|c|}{22} \\
\hline Non-tumor bearing rats & \multicolumn{2}{|c|}{2 (out of 19) } & \multicolumn{2}{|c|}{7 (out of 19) } & \multicolumn{2}{|c|}{7 (out of 20 ) } \\
\hline
\end{tabular}

Dominant type in mixed tumors is the first in order. Non-tumor-bearing rats (one in NMU and one in NMU+ROS10) that died before the termination of the experiment were not considered.

Abbreviations: NMU - control group, NMU+ROS10 - chemoprevention with rosiglitazone (10 ppm), NMU+ROS100 - chemoprevention with rosiglitazone (100 ppm), HG - high-grade, LG - low-grade.

Table 4. Metabolic effects of rosiglitazone in NMU-induced mammary carcinogenesis in Sprague-Dawley rats

\begin{tabular}{|c|c|c|c|c|}
\hline & INT & NMU & NMU+ROS10 & NMU+ROS100 \\
\hline $\mathbf{n}$ & 10 & 19 & 19 & 20 \\
\hline \multicolumn{5}{|l|}{ SERUM } \\
\hline GLU (mmol/l) & $4.51 \pm 0.133$ & $4.97 \pm 0.0951$ aa & $4.05 \pm 0.146 \downarrow \downarrow \downarrow$ & $4.96 \pm 0.0914 \mathbf{b b b}$ \\
\hline INS (ng/ml) & $0.249 \pm 0.0405$ & $0.185 \pm 0.0221$ & $0.0872 \pm 0.0160 \downarrow$ & $0.220 \pm 0.0195 \mathbf{b b b}$ \\
\hline TAG (mmol/l) & $0.423 \pm 0.0451$ & $0.605 \pm 0.0310 \mathrm{aa}$ & $0.581 \pm 0.0290$ & $0.640 \pm 0.0308$ \\
\hline $\mathrm{CH}(\mathrm{mmol} / \mathrm{l})$ & $3.95 \pm 0.246$ & $3.38 \pm 0.110 \mathrm{a}$ & $3.74 \pm 0.160$ & $4.59 \pm 0.197 \uparrow \uparrow \uparrow \mathbf{b b}$ \\
\hline $\mathrm{PL}(\mathrm{mmol} / \mathrm{l})$ & $1.91 \pm 0.117$ & $1.71 \pm 0.0766$ & $1.92 \pm 0.0878$ & $2.23 \pm 0.106 \uparrow \uparrow \mathbf{b}$ \\
\hline CTS (ng/ml) & $542 \pm 84.9$ & $477 \pm 70.7$ & $811 \pm 112 \uparrow$ & $512 \pm 63.8$ \\
\hline IGF-1 (ng/ml) & $609 \pm 46.2$ & $562 \pm 44.6$ & $749 \pm 30.4 \uparrow \uparrow$ & $617 \pm 41.5 \mathbf{b}$ \\
\hline \multicolumn{5}{|l|}{ LIVER } \\
\hline absolute weight (g) & $7.01 \pm 0.184$ & $6.94 \pm 0.177$ & $7.05 \pm 0.170$ & $8.39 \pm 0.236 \uparrow \uparrow \uparrow \mathbf{b b b}$ \\
\hline relative weight (\%) & $2.48 \pm 0.0623$ & $2.73 \pm 0.0476$ aa & $2.83 \pm 0.0479$ & $3.28 \pm 0.0762 \uparrow \uparrow \uparrow \mathbf{b b b}$ \\
\hline $\mathrm{GLY}(\mu \mathrm{mol} / \mathrm{g})$ & $38.3 \pm 1.65$ & $46.3 \pm 2.44 \mathbf{a}$ & $20.0 \pm 2.12 \downarrow \downarrow \downarrow$ & $32.5 \pm 3.22 \downarrow \downarrow \mathbf{b b}$ \\
\hline $\mathrm{TAG}(\mu \mathrm{mol} / \mathrm{g})$ & $31.8 \pm 1.93$ & $21.3 \pm 2.04$ aa & $32.1 \pm 2.01 \uparrow \uparrow \uparrow$ & $20.2 \pm 1.46 \mathbf{b b b}$ \\
\hline $\mathrm{CH}(\mu \mathrm{mol} / \mathrm{g})$ & $39.2 \pm 2.47$ & $34.6 \pm 1.61$ & $26.6 \pm 0.971 \downarrow \downarrow \downarrow$ & $26.0 \pm 0.640 \downarrow \downarrow \downarrow$ \\
\hline $\mathrm{PL}(\mu \mathrm{mol} / \mathrm{g})$ & $44.2 \pm 1.73$ & $43.5 \pm 1.87$ & $36.4 \pm 1.20 \downarrow \downarrow$ & $37.5 \pm 1.45 \downarrow$ \\
\hline MDA (nmol/g) & $42.3 \pm 1.35$ & $49.5 \pm 2.05 \mathrm{a}$ & $45.0 \pm 2.58$ & $37.2 \pm 1.39 \downarrow \downarrow \downarrow \mathbf{b}$ \\
\hline \multicolumn{5}{|l|}{ HEART MUSCLE } \\
\hline absolute weight (g) & $0.875 \pm 0.339$ & $0.821 \pm 0.0138$ & $0.855 \pm 0.0193$ & $1.15 \pm 0.0302 \uparrow \uparrow \uparrow \mathbf{b b b}$ \\
\hline relative weight (\%) & $0.308 \pm 0.00708$ & $0.324 \pm 0.00548$ & $0.340 \pm 0.00518 \uparrow$ & $0.453 \pm 0.0773 \uparrow \uparrow \uparrow \mathbf{b b b}$ \\
\hline GLY $(\mu \mathrm{mol} / \mathrm{g})$ & $32.5 \pm 3.04$ & $41.1 \pm 2.42$ & $26.9 \pm 0.799 \downarrow \downarrow \downarrow$ & $26.3 \pm 1.08 \downarrow \downarrow \downarrow$ \\
\hline \multicolumn{5}{|l|}{ THYMUS } \\
\hline absolute weight (g) & $0.246 \pm 0.0223$ & $0.206 \pm 0.0112$ & $0.203 \pm 0.00803$ & $0.197 \pm 0.00963$ \\
\hline relative weight (\%) & $0.0868 \pm 0.00771$ & $0.0818 \pm 0.00489$ & $0.0810 \pm 0.00336$ & $0.0785 \pm 0.00423$ \\
\hline MDA (nmol/g) & $21.6 \pm 1.76$ & $23.6 \pm 0.979$ & $28.0 \pm 1.24 \uparrow \uparrow$ & $21.1 \pm 1.24 \mathbf{b b b}$ \\
\hline
\end{tabular}

Data are expressed as means \pm S.E.M. Significant differences between groups are designated as follows: NMU vs INT: a P $\leq 0.05$, aa $\mathrm{P} \leq 0.01$; a decrease of given parameter in groups with chemoprevention (NMU+ROS10, NMU+ROS100) vs NMU: $\downarrow \mathrm{P} \leq 0.05, \downarrow \downarrow \mathrm{P} \leq 0.01, \downarrow \downarrow \downarrow \mathrm{P} \leq 0.001$; an increase of given parameter in groups with chemoprevention (NMU+ROS10, NMU+ROS100) vs NMU: $\uparrow \mathrm{P} \leq 0.05$, $\uparrow \uparrow ~ P \leq 0.01$, $\uparrow \uparrow \uparrow ~ P \leq 0.001$; NMU+ROS10 vs NMU+ROS100: b P $\leq 0.05, \mathbf{b b} \mathrm{P} \leq 0.01, \mathbf{b b b} \mathrm{P} \leq 0.001$. Abbreviations: NMU - control group without chemoprevention; NMU+ROS10 - chemoprevention with rosiglitazone (10 ppm), NMU+ROS100 - chemoprevention with rosiglitazone (100 ppm), INT - intact group, $\mathrm{n}$ - number of animals per group, GLU - glucose, TAG - triacylglycerols, PL - phospholipids, $\mathrm{CH}$ - cholesterol, CTS - corticosterone, INS - insulin, IGF-1 - insulin-like growth factor 1, GLY - glycogen, MDA - malondialdehyde 
ROS is now available only through a restricted access program. ROS use was also associated with fluid retention and weight gain [51].

In this work we evaluated effects of ROS administered in a diet at two concentrations: $10 \mathrm{ppm}$ and $100 \mathrm{ppm}$ which correspond to average daily intake of $0.18 \mathrm{mg} / \mathrm{rat} / \mathrm{day}$ and $1.8 \mathrm{mg} / \mathrm{rat} /$ day, respectively. Considering body area surface, our lower ROS dose was comparable with the therapeutic dose used in human treatment (maximum dose: $8 \mathrm{mg} /$ day). ROS administration had no effect on weight loss (and periovarial fat weight loss) in rats administered with carcinogen despite tendency to normalise food intake (at higher dose). Similarly, no effect on body weight gain was recoreded in the same experimental model using pioglitazone although higher pioglitazone dose (100 ppm in a diet) increased food intake and insignificantly periovarial fat weight too [52]. Asp et al. [53] reported initial weight loss delay and adipose depletion attenuation in mice with cancer cachexia administered with ROS, which, however, did not persist, food intake eventually declined as well. It seems that ROS cannot prevent weight loss in cancer subjects (which is mostly mediated by inflammatory cytokines) regardless of changes in food intake.

NMU-induced mammary tumors appear to be more estrogen-dependent, while mammary tumors induced by 7,12-dimethylbenz(a)anthracene (a procarcinogen) seem to be more prolactin-dependent [54]. It was reported that estrogen receptor $\beta(E R \beta)$ can inhibit ligand-mediated PPAR $\gamma$ - transcriptional activity and subsequently block PPAR $\gamma$-induced gene expression. As we reported before, NMU-induced tumors in Sprague-Dawley rats show strong positivity for both ER $\alpha$ and ER $\beta$ [55] which can interfere with thiazolidinedione activity. Neither higher nor lower ROS dose significantly altered tumor growth with the exception of decreased tumor frequency per group after higher ROS dose (by 44\%). Still, NMU+ROS10 group showed best histopathology profile with low-grade tumors prevalence, in NMU and NMU+ROS100 group high-grade/low-grade tumor ratio was balanced. The antitumor effect of the other thiazolidinedione, pioglitazone was better, in our previous work higher dose of pioglitazone (100 ppm) in the same experimental model significantly decreased tumor frequency per group (by 63\%) and lengthened the latency period (by $32 \%)$ [36].

The effect of ROS in NMU-induced rat mammary carcinogenesis was evaluated by Nunez et al. [34] too, but the authors chose curative model and started to administer ROS $(0.06 \mathrm{mg} / \mathrm{kg} / \mathrm{rat})$ when tumor reached certain size, daily for 25 days. Histopathology showed $45 \%$ of tumors responded to ROS administration, the responsiveness increased in combined treatment of ROS and tamoxifen. ROS seems to be more effective in DMBA model as Kocdor et al. [35] recorded no malignant tumor after ROS administration $(0.2 \mathrm{mg} / \mathrm{kg}$ via gavage, 2 weeks prior to and 1 week after the carcinogen application). The authors found high plasma prolactin but not estrogen levels, ROS probabaly protected mammary gland from prolactin effects.

Higher serum IGF-1 is associated with increased cancer risk including breast cancer [56], but in advanced cancer stages circulating IGF-1 levels decline, both in animals [57] and humans [58]. This was proved in our previous work with metformin [59] but not in this experiment, in NMU+ROS10 group, however, serum IGF-1 increased unexpectedly. Nunez et al. [34] and Kocdor et al. [35] found no changes in serum IGF-1 level after ROS administration and similarly, pioglitazone administration did not change serum IGF-1 level [52].

Serum cortisol increases in breast cancer patients, especially in those with weight loss [60], serum CTS increased in control animals (administered with NMU) in our previous reports too and chemoprevention (with metformin and pioglitazone, respectively) [59,52] decreased it. Surprisingly, in this work serum CTS was not changed after higher ROS dose and even rose after lower ROS dose, while metformin and particularly pioglitazone markedly decreased serum CTS [59,52]; this might contribute to lack of ROS antitumor efficacy as glucocorticoids can inhibit apoptosis in mammary epithelial cells $[61,62]$.

Increased glucose turnover is the hallmark of carbohydrate metabolism in cancer cachexia. In tumor-bearing subjects gluconeogenesis is enhanced and plasma glucose clearance increases due to large glucose consumption in tumors and, as a result, plasma INS decreases. However, according to some authors, the decreased INS concentrations are secondary to the decreased food intake and not the presence of a tumor per se $[63,64]$. In this work, lower ROS dose decreased glycaemia and insulinaemia but glycaemia values in all groups remained in the normal range, as they did in previous reports with metformin and pioglitazone administration, respectively $[59,52]$. No changes in serum INS after ROS administration were reported by Nunez et al. [34] as well. GLY concentration rose in NMU group both in liver and heart muscle and decreased after both ROS doses, we expected contrary results as in previous experiments metformin and pioglitazone restored glycogen values which were decreased in NMU group $[59,52]$

Cancer subjects exhibit lipomobilisation resulting in depletion of adipose tissue and liver TAG and increase in serum TAG. This was seen in our work too, ROS at lower (but not at higher) dose attenuated liver lipomobilisation, though did not change serum TAG levels. In the previous work, pioglitazone had the same effect but only at higher dose. ROS administration led to decreased liver PL concentrations (at both doses) and increased serum PL levels (at higher dose). In our previous work, no changes in PL concentration were recorded [59,52]. Similarly, neither serum PL concentrations nor the spectrum of the individual phospholipids differed between breast cancer patients and healthy women [65]. Lipid metabolism alteration in carcinogensis results in lower total and $\mathrm{HDL} \mathrm{CH}$ in serum $[60,66]$. Lower serum total $\mathrm{CH}$ was recorded in NMU group, ROS administration increased it (significantly at higher dose). 
Both ROS doses markedly decreased liver $\mathrm{CH}$ concentration. In our previous work pioglitazone administration did not change serum and liver $\mathrm{CH}$ concentration [52].

In both cancer disease and diabetes increased oxidative damage was seen $[67,68]$, this may be a result of increased reactive oxygen species formation and/or attenuated antioxidant capacity. Reactive oxygen species enhance lipid peroxidation which results in higher MDA production. Increased lipoperoxidation in liver after carcinogen administration was seen in this as well as in our previous experiments and peroral antidiabetics metformin, pioglitazone, and ROS at higher dose exerted clear protective effects $[59,52]$. In thymus, however, MDA concentration in NMU goup did not differ from intact value and even rose after lower ROS dose. Nevertheless, our results indicate peroral antidiabetics may have a role in maintaining biomembrane integrity through lipid peroxidation inhibition.

Cardiovascular safety of ROS remains important issue. Although its use does not increase overall cardiovascular mortality, previously suspected increased heart failure risk [69] was confirmed [50]. ROS induces cardiac hypertrophy which may occur via PPAR $\gamma$-independent effects in cardiomyocytes or PPAR $\gamma$ in nonmyocyte cells or may be secondary to blood volume expansion $[51,70]$. In our work ROS administered at higher dose induced prominent cardiac hypertrophy, both absolute and relative heart muscle weight increased by $40 \%$. Lower ROS dose increased relative heart muscle weight when compared to NMU group too (though only by $5 \%$ ). It should be noted, however, that our higher dose was about 10 -fold higher than those used in diabetes treatment (considering body surface). So far, human data have not challenged the cardiovascular safety of another thiazolidinedione pioglitazone which may even exert cardioprotective effect [71], yet, in our previous work, higher dose of pioglitazone increased relative heart muscle weight by $7 \%$ (unpublished data), so possible cardiovascular risk of pioglitazone should be monitored.

Comparing ROS and pioglitazone anticancer efficacy and metabolic impact in NMU-induced rat mammary carcinogenesis model, ROS seems to exert less chemopreventive potential, but both substances can alleviate some unfavourable metabolic alterations resulting from cancer progression such as liver lipid peroxidation. However, side effects of thiazolidinediones (particularly risk of cardiac hypertrophy) must not be omitted and new analogues such as rivoglitazone (which is currently under research for use) should be carefully evaluated before their use in diabetes treatment, which, in most cases, is long lasting.

Acknowledgements: This work was supported by the Grant Science Agency, Ministry of Education, Slovak Republic, project No. 1/4321/07 and Slovak Research and Development Agency under contract No. VVCE-0001-07. The experiment was approved by the State Veterinary and Food Administration of Slovak Republic, accreditation No. Ro-1575/10-221.
The authors wish to thank Ingrid Obsitosova and Eva Petrovicova from technical staff for their excellent assistance, as well as Dr. Natalia Kokosova, Dr. Beata Kalatova and Dr. Zuzana Papcova for their useful assistance in metabolic and data analysis.

\section{References}

[1] CZYZYK A, SZCZEPANIK Z Diabetes mellitus and cancer. Eur J Intern Med 2000; 11: 245-252. http://dx.doi.org/10.1016/ S0953-6205(00)00106-0

[2] VIGNERI P, FRASCA F, SCIACCA L, PANDINI G, VIGNERI R Diabetes and cancer. Endocr-Relat Cancer 2009; 16: 1103-1123. http://dx.doi.org/10.1677/ERC-09-0087

[3] GALLAGHER EJ, LEROITH D Diabetes, cancer, and metformin: connections of metabolism and cell proliferation. Ann NY Acad. Sci 2011; 1243: 54-68. http://dx.doi.org/10.1111/ j.1749-6632.2011.06285.x

[4] HAY N, SONENBERG N Upstream and downstream of mTOR. Genes Dev 2004; 18: 1926-1945. http://dx.doi. org/10.1101/gad.1212704

[5] WICKI A, HAGMANN J Diet and cancer. Swiss Med Wkly 2011; 141: w13250.

[6] DAZERT E, HALL MN mTOR signalling in disease. Curr Opin Cell Biol 2011; 23: 744-755. http://dx.doi.org/10.1016/ j.ceb.2011.09.003

[7] INOKI K, KIM J, GUAN K-L AMPK and mTOR in Cellular Energy Homeostasis and Drug Targets. Annu Rev Pharmacol Toxicol 2012; 52: 381-400. http://dx.doi.org/10.1146/annurevpharmtox-010611-134537

[8] FOGARTY S, HARDIE DG Development of protein kinase activators: AMPK as a target in metabolic disorders and cancer. BBA-Proteins Proteom 2010; 1804: 581-591.

[9] DOWLING RJO, NIRAULA S, STAMBOLIC V, GOODWIN PJ Metformin in Cancer: Translational Challenges. J Mol Endocrinol 2012; 48: R31-E43. http://dx.doi.org/10.1530/ IME-12-0007

[10] ELROD HA, SUN Y-H PPAR $\gamma$ and Apoptosis in Cancer. PPAR Research 2008, Article ID 704165, doi: 10.1155/2008/704165. http://dx.doi.org/10.1155/2008/704165

[11] HATTON JL, YEE LD Clinical Use of PPAR $\gamma$ Ligands in Cancer. PPAR Research 2008; Article ID 159415, doi: 10.1155/ 2008/159415. http://dx.doi.org/10.1155/2008/159415

[12] ROBBINS GT, NIE D PPAR gamma, bioactive lipids, and cancer progression. Front Biosci 2012; 17: 1816-1834. http:// dx.doi.org/10.2741/4021

[13] CHINETTI G, FRUCHART JC, STAELS B Peroxisome proliferator-activated receptors (PPARs): Nuclear receptors at the crossroads between lipid metabolism and inflammation. Inflamm Res 2000; 49: 497-505. http://dx.doi.org/10.1007/ s000110050622

[14] PALAKURTHI SS, AKTAS H, GRUBISSICH LM, MORTENSEN RM, HALPERIN JA Anticancer effects of thiazolidinediones are independent of peroxisome proliferator-activated receptor $\gamma$ and mediated by inhibition of translation initiation. Cancer Res 2001; 61: 6213-6218.

[15] WEI S, YANG J, LEE S-L, KULP SK, CHEN C-S PPAR $\gamma$ independent antitumor effects of thiazolidinediones. 
Cancer Lett 2009; 276: 119-124. http://dx.doi.org/10.1016/ j.canlet.2008.08.008

[16] FRYER LGD, PARBU-PATEL A, CARLING D The anti-diabetic drugs rosiglitazone and metformin stimulate AMP-activated protein kinase through distinct signaling pathways. J Biol Chem 2002; 277: 25226-25232. http://dx.doi.org/10.1074/jbc. M202489200

[17] SAHA AK, AVILUCEA PR, YE J-M, ASSIFI MM, KRAEGEN EW et al. Pioglitazone treatment activates AMP-activated protein kinase in rat liver and adipose tissue in vivo. Biochem Bioph Res Co 2004; 314: 580-585. http://dx.doi.org/10.1016/ j.bbrc.2003.12.120

[18] RUBIN GL, ZHAO Y, KALUS AM, SIMPSON ER Peroxisome proliferator-activated receptor- $\gamma$ ligands inhibit oestrogen biosynthesis in human breast adipose tissue: possible implications for breast cancer therapy. Cancer Res 2000; 60: 1604-1608.

[19] GROMMES C, LANDRETH GE, SASTRE M, BECK M, FEINSTEIN DL et al. Inhibition of in vivo glioma growth and invasion by peroxisome proliferator-activated receptor $\gamma$ agonist treatment. Mol Pharmacol 2006; 70: 1524-1533. http://dx.doi.org/10.1124/mol.106.022194

[20] PAPI A, TATENHORST L, TERWEL D, HERMES M, KUMMER MP et al. PPAR $\gamma$ and RXR $\gamma$ ligands act synergistically as potent antineoplastic agents in vitro and in vivo glioma models. J Neurochem 2009; 109: 1779-1790. http://dx.doi. org/10.1111/j.1471-4159.2009.06111.x

[21] KRIEGER-HINCK N, SCHUMACHER U, MULLER A, VALENTINER U The effect of the PPAR- $\gamma$ agonist rosiglitazone on neuroblastoma SK-N-SH cells in a metastatic xenograft mouse model. Oncol Res 2010; 18: 387-393. http://dx.doi. org/10.3727/096504010X12644422320708

[22] CELLAI I, PETRANGOLINI G, TORTORETO M, PRATESI $G$, LUCIANI $P$ et al. In vivo effects of rosiglitazone in a human neuroblastoma xenograft. Brit J Cancer 2010; 102: 685-692. http://dx.doi.org/10.1038/sj.bjc.6605506

[23] LYON CM, KLINGE DM, DO KC, GRIMES MJ, THOMAS $\mathrm{CL}$ et al. Rosiglitazone prevents the progression of preinvasive lung cancer in a murine model. Carcinogenesis 2009; 30: 2095-2099. http://dx.doi.org/10.1093/carcin/bgp260

[24] TAKEUCHI Y, TAKAHASHI M, SAKANO K, MUTOH M, NIHO N et al. Suppression of N-nitrosobis(2-oxopropyl)amineinduced pancreatic carcinogenesis in hamsters by pioglitazone, a ligand of peroxisome proliferator-activated receptor $\gamma$. Carcinogenesis 2007; 28: 1692-1696. http://dx.doi.org/ $10.1093 /$ carcin/bgm095

[25] GUO Y-T, LENG X-S, LI T, ZHAO J-M, LIN X-H Peroxisome proliferator-activated receptor $\gamma$ ligands suppress liver carcinogenesis induced by diethylnitrosamine in rats. World J Gastroenterol 2004; 10: 3419-3423.

[26] BORBATH I, LECLERCQ I, MOULIN P, SEMPOUX C, HORSMANS Y The PPARgamma agonist pioglitazone inhibits early neoplastic occurrence in the rat liver. Eur J Cancer 2007; 43: 1755-1763. http://dx.doi.org/10.1016/ j.ejca.2007.05.005

[27] SHEN B, CHU ES, ZHAO G, MAN K, WU CW et al. PPARgamma inhibits hepatocellular carcinoma metastases in vitro and in mice. Br J Cancer 2012; 106: 1486-1494. http://dx.doi. org/10.1038/bjc.2012.13

[28] TAKANO S, KUBOTA T, NISHIBORI H, HASEGAWA H, ISHII Y et al. Pioglitazone, a ligand for peroxisome proliferator-activated receptor- $\gamma$ acts as an inhibitor of colon cancer liver. Anticancer Res 2008; 28: 3593-3599.

[29] LUCONI M, MANGONI M, GELMINI S, POLI G, NESI G et al. Rosiglitazone impairs proliferation of human adrenocortical cancer: Preclinical study in a xenograft mouse model. Endocrine-Relat Cancer 2010; 17: 169-177. http://dx.doi. org/10.1677/ERC-09-0170

[30] YOKOYAMA Y, XIN B, SHIGETO T, MIZUNUMA H Combination of ciglitazone, a peroxisome proliferator-activated receptor gamma ligand, and cisplatin enhances the inhibition of growth of human ovarian cancers. J Cancer Res Clin Oncol 2011; 137: 1219-1228. http://dx.doi.org/10.1007/s00432-0110993-1

[31] SHIGETO T, YOKOYAMA Y, XIN B, MIZUNUMA H. Peroxisome proliferator-activated receptor alpha and gamma ligands inhibit the growth of human ovarian cancer. Oncol Rep 2007; 18: 833-840.

[32] BOTTON T, PUISSANT A, BAHADORAN P, ANNICOTTE $\mathrm{J}$-S, FAJAS $\mathrm{L}$ et al. In vitro and in vivo anti-melanoma effects of ciglitazone. J Invest Dermatol 2009; 129: 1208-1218. http:// dx.doi.org/10.1038/jid.2008.346

[33] ELSTNER E, MULLER C, KOSHIZUKA K, WILLIAMSON EA, PARK D et al. Ligands for peroxisome proliferator-activated receptory and retinoic acid receptor inhibit growth and induce apoptosis of human breast cancer cells in vitro and in BNX mice. P Natl Acad Sci USA 1998; 95: 8806-8811. http://dx.doi.org/10.1073/pnas.95.15.8806

[34] NUNEZ M, MARTIN G, COCCA C, MOHAMAD N, GUTIERREZ A et al. Effect of rosiglitazone on N-nitroso$\mathrm{N}$-methylurea-induced mammary tumors in rat. Anticancer Res 2006; 26: 2113-2122.

[35] KOCDOR H, KOCDOR MA, CANDA T, GUREL D, CEHRELI R et al. Chemopreventive efficacies of rosiglitazone, fenretinide and their combination against rat mammary carcinogenesis. Clin Transl Oncol 2009; 11: 243-249. http:// dx.doi.org/10.1007/s12094-009-0347-5

[36] BOJKOVA B, GARAJOVA M, KAJO K, PEC M, KUBATKA $\mathrm{P}$ et al. Pioglitazone in chemically induced mammary carcinogenesis in rats. Eur J Cancer Prev 2010; 19: 379-384. http://dx.doi.org/10.1097/CEJ.0b013e32833ca233

[37] CHANG C-H, LIN J-W, WU L-C, LAI M-S, CHUANG L-M et al. Association of thiazolidinediones with liver cancer and colorectal cancer in type 2 diabetes mellitus. Hepatology 2012; 55: 1462-1472. http://dx.doi.org/10.1002/hep.25509

[38] GOVINDARAJAN R, RATNASINGHE L, SIMMONS DL, SIEGEL ER, MIDATHADA MV et al. Thiazolidinediones and the risk of lung, prostate, and colon cancer in patients with diabetes. J Clin Oncol 2007; 25: 1476-1481. http://dx.doi. org/10.1200/JCO.2006.07.2777

[39] KORO C, BARRETT C, QIZILBASH N Cancer risks in thiazolidinedione users compared to other anti-diabetic agents. Pharmacoepidem Dr S 2007; 16: 485-492. http://dx.doi. org/10.1002/pds.1352 
[40] MONAMI M, LAMANNA C, MARCHIONNI N, MANNUCCI E Rosiglitazone and risk of cancer: A meta-analysis of randomized clinical trials. Diabetes Care 2008; 31: 1455-1460. http://dx.doi.org/10.2337/dc07-2308

[41] RAMOS-NINO ME, MACLEAN CD, LITTENBERG B Association between cancer prevalence and use of thiazolidinediones: Results from the Vermont Vermont Diabetes Information System. BMC Medicine 2007; 5: 17. http://dx.doi. org/10.1186/1741-7015-5-17

[42] DORMANDY JA, CHARBONNEL B, ECKLAND DJ, ERDMANN E, MASSI-BENEDETTI $M$ et al. Secondary prevention of macrovascular events in patients with type 2 diabetes in the PROactive study (PROspective pioglitAzone clinical trial in macroVascular events): A randomised controlled trial. Lancet 2005; 366: 1279-1289. http://dx.doi. org/10.1016/S0140-6736(05)67528-9

[43] BARBALAT Y, DOMBROVSKIY VY, WEISS RE Association between pioglitazone and urothelial bladder cancer. Urology 2012; 80:1-4. http://dx.doi.org/10.1016/ j.urology.2012.03.032

[44] RUSSO J, RUSSO IH Atlas and histologic classification of tumors of the rat mammary gland. J Mammary Gland Biol Neoplasia 2000; 5: 187-200. http://dx.doi.org/10.1023/ A:1026443305758

[45] BARTLETT GR Phosphorus assay in column chromotheraphy. J Biol Chem 1959; 234: 466-468.

[46] ZLATKIS A, ZAK B, BOYLE AJ A new method for the direct determination of cholesterol. J Lab Clin Med 1953; 41: 486-492.

[47] ROE JH, DAILEY RE Determination of glycogen with the anthrone reagent. Anal Biochem 1966; 15: 245-250. http:// dx.doi.org/10.1016/0003-2697(66)90028-5

[48] SATOH K Serum lipid peroxide in cerebrovascular disorders determined by a new colorimetric method. Clin Chim Acta 1978; 90: 37-43. http://dx.doi.org/10.1016/00098981(78)90081-5

[49] GUILLEMIN R, CLAYTON GW, SMITH JD, LIPSCOMB HS Measurement of free corticosteroids in rat plasma. Physiological validation of the method. Endocrinology 1958; 63: 349-355. http://dx.doi.org/10.1210/endo-63-3-349

[50] NISSEN SE, WOLSKI K Rosiglitazone revisited: An updated meta-analysis of risk for myocardial infarction and cardiovascular mortality. Arch Intern Med 2010; 170: 1191-1201. http://dx.doi.org/10.1001/archinternmed.2010.207

[51] NESTO RW, BELL D, BONOW RO, FONSECA V, GRUNDY $\mathrm{SM}$ et al. Thiazolidinedione use, fluid retention, and congestive heart failure: A consensus statement from the American Heart Association and American Diabetes Association. Circulation 2003; 108: 2941-2948. http://dx.doi.org/10.1161/01. CIR.0000103683.99399.7E

[52] BOJKOVA B, GARAJOVA M, PEC M, KUBATKA P, KAJO $\mathrm{K}$ et al. Metabolic Effects of Pioglitazone in Chemically-Induced Mammary Carcinogenesis in Rats. Pathol Oncol Res 2011; 17: 887-892. http://dx.doi.org/10.1007/s12253-0119399-2

[53] ASP ML, TIAN M, KLIEWER KL, BELURY MA Rosiglitazone delayed weight loss and anorexia while attenuating adipose depletion in mice with cancer cachexia. Cancer Biol Ther 2011; 12: 957-965. http://dx.doi.org/10.4161/ cbt.12.11.18134

[54] THOMPSON HJ, SINGH M Rat models of premalignant breast disease. J Mammary Gland Biol Neoplasia 2000; 5: 409-420. http://dx.doi.org/10.1023/A:1009582012493

[55] KISKOVA T, EKMEKCIOGLU C, GARAJOVA M, ORENDAS P, BOJKOVA B et al. A combination of resveratrol and melatonin exerts chemopreventive effects in N-methyl-Nnitrosourea-induced rat mammary carcinogenesis. Eur J Cancer Prev 2012; 21: 163-170. http://dx.doi.org/10.1097/ CEJ.0b013e32834c9c0f

[56] HANKINSON SE, WILLETT WC, COLDITZ GA, HUNTER DJ, MICHAUD DS et al. Circulating concentrations of insulinlike growth factor-I and risk of breast cancer. Lancet 1998; 351: 1393-1396. http://dx.doi.org/10.1016/S0140-6736(97)10384-1

[57] COSTELLI P, MUSCARITOLI M, BOSSOLA M, PENNA F, REFFO P et al. IGF-1 is downregulated in experimental cancer cachexia. Am J Physiol-Reg I 2006; 291: 674-683.

[58] MAZZOCCOLI G, GIULIANI A, BIANCO G, DE CATA A, BALZANELLI $M$ et al. Decreased serum levels of insulin-like growth factor (IGF)-I in patients with lung cancer: Temporal relationship with growth hormone (GH) levels. Anticancer Res 1999; 19: 1397-1399.

[59] BOJKOVA B, ORENDAS P, GARAJOVA M, KASASYOVA M, KUTNA V Metformin in chemically-induced mammary carcinogenesis in rats. Neoplasma 2009; 56: 269-274. http:// dx.doi.org/10.4149/neo $200903 \quad 269$

[60] KNAPP ML, AL-SHEIBANI S, RICHES PG, HANHAM IWF, PHILLIPS RH Hormonal factors associated with weight loss in patients with advanced breast cancer. Ann Clin Biochem 1991; 28: 480-486.

[61] FENG Z, MARTI A, JEHN B, ALTERMATT HJ, CHICAIZA $\mathrm{G}$ et al. Glucocorticoid and progesterone inhibit involution and programmed cell death in the mouse mammary gland. J Cell Biol 1995; 131: 1095-1103. http://dx.doi.org/10.1083/ jcb.131.4.1095

[62] SCHORR K, FURTH PA Induction of bcl-x(L) expression in mammary epithelial cells is glucocorticoid-dependent but not signal transducer and activator of transcription 5-dependent. Cancer Res 2000; 60: 5950-5953.

[63] SVANINGER G, DROTT C, LUNDHOLM K Role of insulin in development of cancer cachexia in nongrowing sarcoma-bearing mice: special reference to muscle wasting. J Natl Cancer Inst 1987; 78: 943-950.

[64] CHANCE WT, THOMAS I, FISCHER JE Insulin reverses ammonia-induced anorexia and experimental cancer anorexia. Nutr Cancer 1994; 21: 213-222. http://dx.doi.org/10.1080/ $\underline{01635589409514320}$

[65] TIMOVSKA Y, PIVNYUK V, TODOR I, ANIKUSKO N, CHEKHUN V The spectrum of blood serum lipids in pateints with breast cancer withou metbolic syndrome. Exp Oncol 2011; 33: 190-192.

[66] KOKOGLU E, KARAARSLAN I, KARAARSLAN HM, BALOGLU H Alterations of serum lipids and lipoproteins in breast cancer. Cancer Lett 1994; 82: 175-178. http://dx.doi. org/10.1016/0304-3835(94)90008-6 
[67] WEST IC Radicals and oxidative stress in diabetes. Diabetic Med 2000; 17: 171-180. http://dx.doi.org/10.1046/j.14645491.2000.00259.x

[68] DROGE W Free radicals in the physiological control of cell function. Physiol Rev 2002; 82: 47-95.

[69] MANNUCCI E, MONAMI M Is the evidence from clinical trials for cardiovascular risk or harm for glitazones convincing? Curr Diabetes Rep 2009; 9: 342-347. http://dx.doi. org/10.1007/s11892-009-0054-1
[70] ARAKAWA K, ISHIHARA T, AOTO M, INAMASU M, KITAMURA K et al. An antidiabetic thiazolidinedione induces eccentric cardiac hypertrophy by cardiac volume overload in rats. Clin Exp Pharmacol Physiol 2004; 31: 8 -13. http://dx.doi. org/10.1111/j.1440-1681.2004.03954.x

[71] CARIOU B, CHARBONNEL B, STAELS B Thiazolidinediones and PPAR $\gamma$ agonists: time for a reassessment. Trends Endocrin Met 2012; 23: 205-215. http://dx.doi.org/10.1016/ j.tem.2012.03.001 